\title{
Avaliação da utilização de fitogênicos em combinação ou não com leveduras em substituição a antibióticos para frangos de corte
}

Evaluation of the use of phytogenics in combination or not with yeasts to replace antibiotics for broilers

Evaluación del uso de fitogénicos en combinación o no con levaduras para reemplazar antibióticos

para pollos de engorde

Fernanda Danieli Antoniazzi Valentini ORCID: https://orcid.org/0000-0002-2868-8498 Universidade do Oeste de Santa Catarina, Brasil

E-mail: fernanda_antoniazzi@ hotmail.com

Lucas Eduardo Talian

ORCID: https://orcid.org/0000-0002-0104-8167 Universidade do Oeste de Santa Catarina, Brasil E-mail: lucastalianagro@gmail.com

Marcos de Lima

ORCID: https://orcid.org/0000-0001-9685-5414 Universidade do Oeste de Santa Catarina, Brasil E-mail: marcosmjlima@gmail.com

Edemar Aniecevski

ORCID: https://orcid.org/0000-0001-6095-7187 Universidade do Oeste de Santa Catarina, Brasil E-mail: edemar3004@gmail.com

Gustavo Zaccaron

ORCID: https://orcid.org/0000-0002-7120-4911 Universidade do Oeste de Santa Catarina, Brasil E-mail: zaccagustavo@gmail.com

Gabriela Miotto Galli

ORCID: https://orcid.org/0000-0001-6734-8659 Universidade Federal do Rio Grande do Sul, Brasil E-mail: gabi-gmg@hotmail.com

Fernando de Castro Tavernari ORCID: https://orcid.org/0000-0002-3161-019X Embrapa Suínos e Aves, Brasil

E-mail: fernando.tavernari@embrapa.br

Aleksandro Schafer da Silva ORCID: https://orcid.org/0000-0001-5459-3823 Universidade do Estado de Santa Catarina, Brasil E-mail: aleksandro.silva@udesc.br

Tiago Goulart Petrolli

ORCID: https://orcid.org/0000-0002-6175-5939 Universidade do Oeste de Santa Catarina, Brasil E-mail: tiago.petrolli@unoesc.edu.br

\section{Resumo}

Objetivou-se avaliar a inclusão de uma combinação de carvacrol + cinnamaldeído e outra de carvacrol + cinnamaldeído + leveduras sobre o desempenho, rendimento de órgãos, morfometria intestinal e parâmetros 
bioquímicos séricos em frangos de corte. Foram utilizados 360 pintos de corte fêmeas da linhagem COBB 500, distribuídos no primeiro dia de idade em delineamento experimental inteiramente casualizado, composto por quatro tratamentos: controle negativo, flavomicina, carvacrol + cinnamaldeído e carvacrol + cinnamaldeído + leveduras, constituídos por seis repetições com 15 animais cada. O blend fitogênicos + leveduras compreendeu o uso de $75 \%$ de leveduras e $25 \%$ de extratos herbais, em sua composição, na fase de $1-21$ dias, $50 \%$ de leveduras e $50 \%$ de extratos herbais em 22-35 dias e $25 \%$ de leveduras e $75 \%$ de extratos herbais em $35-42$ dias. Houve redução $(\mathrm{P}<0,05)$ do peso vivo e do ganho de peso nas aves suplementadas com carvacrol + cinnamaldeído, e a mortalidade foi menor $(\mathrm{P}<0,05)$ nas aves do grupo com Flavomicina. Não houve alterações $(\mathrm{P}>0,05)$ sobre o rendimento de órgãos e a altura das vilosidades intestinais $(\mathrm{P}>0,05)$, entretanto, a profundidade de cripta foi maior $(\mathrm{P}<0,05)$ nas aves suplementadas com Flavomicina. Constatou-se maior relação vilo/crpta $(\mathrm{P}<0,05)$ nos frangos suplementados com fitogênicos + leveduras, em comparação às aves que receberam flavomicina. Não houve diferenças $(\mathrm{P}>0,05)$ entre os parâmetros bioquímicos séricos avaliados. A inclusão de carvacrol e cinnamaldeído + leveduras pode substituir os antibióticos na alimentação de frangos de corte, garantindo adequado desempenho produtivo, sem comprometer o órgãos, morfometria intestinal e a bioquímica sérica.

Palavras-chave: Carvacrol; Cinnamaldeído; Nutrição de aves; Promotor de crescimento.

\begin{abstract}
The objective was to evaluate the inclusion of a combination of carvacrol + cinnamaldehyde and carvacrol + cinnamaldehyde + yeasts on performance, organ yield, intestinal morphometry and serum biochemical parameters in broilers. 360 female broiler chicks of the COBB 500 strain were used, distributed on the first day of age in a completely randomized experimental design, composed of four treatments: negative control, flavomycin, carvacrol + cinnamaldehyde and carvacrol + cinnamaldehyde + yeasts, consisting of six replicates with 15 animals each. The phytogenic + yeast blend comprised the use of $75 \%$ yeast and $25 \%$ herbal extracts, in their composition, in the 1-21 day phase, $50 \%$ yeast and $50 \%$ herbal extracts in 22-35 days and $25 \%$ yeast and $75 \%$ herbal extracts in $35-42$ days. There was a reduction $(\mathrm{P}<0.05)$ in live weight and weight gain in birds supplemented with carvacrol + cinnamaldehyde, and mortality was lower $(\mathrm{P}<0.05)$ in birds in the group with Flavomycin. There were no changes $(\mathrm{P}>$ $0.05)$ in the organ yield and the height of the intestinal villi $(\mathrm{P}>0.05)$, however, the crypt depth was greater $(\mathrm{P}<0.05)$ in birds supplemented with Flavomycin. A higher villus / crypt ratio $(\mathrm{P}<0.05)$ was found in chickens supplemented with phytogenics + yeasts, compared to birds that received flavomycin. There were no differences $(\mathrm{P}>0.05)$ between the serum biochemical parameters evaluated. The inclusion of carvacrol and cinnamaldehyde + yeasts can replace antibiotics in the feed of broilers, guaranteeing adequate productive performance and without compromising organs, intestinal morphometry and serum biochemistry.
\end{abstract}

Keywords: Carvacrol; Cinnamaldehyde; Growth promoters; Poultry nutrition.

\title{
Resumen
}

El objetivo fue evaluar la inclusión de una combinación de carvacrol + cinamaldehído y carvacrol + cinamaldehído + levaduras sobre el rendimiento, rendimiento de órganos, morfometría intestinal y parámetros bioquímicos séricos en pollos. Se utilizaron 360 aves COBB 500, distribuidos el primer día de edad en un diseño experimental completamente aleatorizado, con cuatro tratamientos: control negativo, flavomicina, carvacrol + cinamaldehído y carvacrol + cinamaldehído + levaduras, compuesto por seis réplicas con 15 animales cada. La mezcla fitogénica + levadura consistió en el uso de $75 \%$ de levadura y $25 \%$ de fitogénicos, en su composición, en la fase de 1-21 días, $50 \%$ de levadura y $50 \%$ de fitogénicos en 22-35 días y $25 \%$ de levadura y $75 \%$ fitogénicos en 35-42 días. Hubo una reducción $(\mathrm{P}<0.05)$ en el peso vivo en las aves suplementadas con carvacrol + cinamaldehído, y la mortalidad fue menor $(\mathrm{P}<0.05)$ en las aves del grupo con Flavomicina. No hubo cambios $(\mathrm{P}>0.05)$ en el rendimiento de órganos y la altura de las vellosidades intestinales $(\mathrm{P}>0.05)$, sin embargo, la profundidad de la cripta fue mayor $(\mathrm{P}<0.05)$ en las aves suplementadas con Flavomicina. Se encontró mayor proporción vellosidades/criptas $(\mathrm{P}<0.05)$ en pollos suplementados con fitogénicos + levaduras, en comparación con aves que recibieron flavomicina. No hubo diferencias $(\mathrm{P}>0,05)$ en los parámetros bioquímicos séricos. La inclusión de levaduras + carvacrol y cinamaldehído puede sustituir a los antibióticos en la alimentación de los pollos, garantizando adecuado rendimiento productivo, sin comprometer órganos, morfometría intestinal y bioquímica sérica.

Palabras clave: Carvacrol; Cinnamaldeído; Nutricción de aves; Promotores de crescimento.

\section{Introduçãa}

Historicamente, sempre foram utilizados antibióticos como a principal alternativa para garantia de saúde intestinal, uma vez que este grupo de moléculas atua suprimindo a carga microbiana intestinal, diminuindo a incidência de bactérias patogênicas no lúmen intestinal e gerando efeitos positivos adicionais. Com mercados cada vez mais exigentes, as empresas e produtores do ramo estão batalhando em busca de alternativas que possam controlar esses desafios em substituição aos antibióticos, utilizados como promotores de crescimento nas rações, o qual atualmente constitui-se no principal desafio da 
Avicultura (Kollanoor-Johny et al., 2012; Alloui Mohamed et al., 2013; Alloui et al., 2014; Oliveira et al., 2014; Spivey et al., 2014). Esta pressão ocorre em virtude das diversas constatações da presença de resíduos de antibióticos nos produtos de origem animal destinados ao consumo da população, com posterior estabelecimento de resistência cruzada nos seres humanos que acabam consumindo frequentemente as carnes e seus derivados contendo estes resíduos.

A união europeia já baniu, desde o ano de 2006, todas as formas de utilização de antibióticos como promotores de crescimento na alimentação animal (Saleh et al., 2017). Neste cenário, já são poucas as moléculas ainda permitidas no Brasil, entretanto, já se sabem que em curto espaço de tempo todos os princípios ativos com caráter antibiótico serão proibidos no país. Diante desta discussão, torna-se necessário buscar novas alternativas ao uso destes aditivos.

A primeira alternativa a ser proposta na presente pesquisa é a utilização de moléculas fitogênicas, oriundas do orégano (carvacrol) e da canela (cinnamaldeído), todas com ampla descrição na literatura dos seus efeitos antimicrobianos (Bosetti et al., 2020). Adicionalmente, outra alternativa disponível e com efeitos semelhantes aos promotores de crescimento é adição de leveduras nos alimentos. Segundo Sassone-Corsi e Raffatellu (2015), as leveduras fornecidas na ração melhoram o equilíbrio da microflora intestinal, através de estimular o crescimento e/ou ativar o metabolismo de algum grupo de bactérias benéficas do trato intestinal, reduzindo patógenos e melhorando consideravelmente os índices zootécnicos, pois são constituídos de microrganismos vivos, os quais são benéficos à flora intestinal, melhorando seu equilíbrio.

O cinnamaldeído, presente no óleo de canela (Cinnamomum verum), tem aumentado a eficiência de utilização dos alimentos com consequente melhor resultado de desempenho (Al-Kassie, 2009). São responsáveis por controlar a atividade antimicrobiana devido à sua lipofilicidade de terpenóides e fenilpropanóides que atravessam a membrana, alcançam o interior das células e danificam o sistema enzimático bacteriano. O extrato de orégano é um óleo essencial extraído e destilado a vapor de plantas híbridas de Origanum vulgare em sua composição, 85\% constituem-se de dois componentes fenóis naturais fundamentais na ação antimicrobiana, o carvacrol e o timol, os quais agem sobre a membrana celular bacteriana impedindo sua divisão mitótica, causando desidratação nas células e, com isso, impedindo a sobrevivências de bactérias patogênicas desempenho (Al-Kassie, 2009), apresentando grande efeito como agente microbiano.

De maneira geral, pesquisadores aprovam que o uso de prebióticos favorecem um bom desempenho dos frangos de corte, ou seja, melhorando a digestibilidade de nutrientes, conforto térmico, bem-estar animal e com um objetivo final redução de custo de produção, saúde pública e aumentando significativamente a lucratividade do produtor rural (Opalinski et al., 2007; Murshed e Abudabos, 2015; Szakacs et al., 2015; Zaghari et al., 2016). As leveduras são fonte de mananoligossacarídeos (MOS), os quais exercem efeitos prebióticos no organismo das aves.

Objetivou-se avaliar o efeito da adição de diversos substitutos a antibióticos como promotores de crescimento em frangos de corte sobre o desempenho (ganho de peso, consumo de ração, conversão alimentar e mortalidade).

\section{Metodologia}

A presente pesquisa foi elaborada de modo quantitativo (Pereira et al., 2018), conduzida nas instalações do laboratório de avicultura da UNOESC Xanxerê, com aprovação do protocolo de pesquisa no comitê de ética da universidade (Parecer CEUA 49/2019). Foram utilizados 360 pintos, fêmeas da linhagem COBB 500, vacinados no incubatório com vacinação inovo contra doença de Marek e Gumboro, e no primeiro dia de vida via spray contra Bronquite Infecciosa.

Foram distribuídos no primeiro dia de idade, em delineamento experimental inteiramente casualizado, sendo composto por quatro tratamentos (Tabela 1), constituídos por seis repetições, com 15 animais em cada repetição. 
Tabela 1 - Tratamentos utilizados.

\begin{tabular}{cll}
\hline Tratamento & Aditivo (g/Ton ou ppm) & Dosagem \\
\hline T1 & Controle negativo & - \\
T2 & Controle positivo - Flavomicina & $15 \mathrm{ppm}$ \\
T3 & Carvacrol e cinnamaldeído & $200 \mathrm{ppm}$ \\
T4 & Blend de Carvacrol e cinnamaldeído + leveduras & $200 \mathrm{ppm}$ \\
\hline
\end{tabular}

Fonte: Autores.

O tratamento contendo carvacrol e cinnamaldeído compreende a utilização dos óleos essenciais microencapsulados do orégano (carvacrol) e canela (cinnamaldeído). O blend dos fitogênicos + leveduras compreendeu o uso de $75 \%$ de leveduras e $25 \%$ de extratos herbais, em sua composição, na fase de 1-21 dias, 50\% de leveduras e 50\% de extratos herbais em 22-35 dias e $25 \%$ de leveduras e $75 \%$ de extratos herbais em 35-42 dias.

Tabela 2 - Programa de aditivos fitogênicos + leveduras, contidos no tratamento 4 (T4).

\begin{tabular}{ccc}
\hline $\begin{array}{c}\text { Idade das aves } \\
\text { (dias) }\end{array}$ & Proporção dos Aditivo no blend & Dosagem do blend na ração \\
\hline $1-21$ & $75 \%$ de leveduras e 25\% de extratos herbais & - \\
$22-28$ & $50 \%$ de leveduras e 50\% de extratos herbais & $200 \mathrm{ppm}$ \\
$29-42$ & $25 \%$ de leveduras e 75\% de extratos herbais & $200 \mathrm{ppm}$ \\
\hline
\end{tabular}

Fonte: Autores.

Os animais foram alojados em boxes de $2 \mathrm{~m}^{2}$ em cama de maravalha e alimentados em comedouros tubular e o fornecimento de água via nipple, conforme as normas e indicações de manejos das granjas comerciais e dos manuais da linhagem. Para a avaliação do consumo da dieta, ganho de peso e conversão alimentar, todas as aves e dietas foram pesadas aos 7, 14, 21, 28 e 42 dias do experimento, para determinação do ganho de peso, do consumo de ração e da conversão alimentar. Adicionalmente, foi calculada a mortalidade e o Índice de Eficiência Produtiva (IEP).

Aos 42 dias do experimento, uma ave por repetição foi eutanasiada, seguindo as normas e recomendações do Guia de práticas de eutanásia do CONCEA (Brasil/MCTI, 2013) e após foram coletados fragmentos do intestino delgado, na porção do mesentério para análise histológica intestinal, as amostras foram processadas e fracionadas em blocos de 4 a $6 \mu \mathrm{m}$, os quais foram corados através de técnicas de hematoxilina-eosina (Labiocel 2002), sendo cujas lâminas foram preparadas no laboratório de Histologia na UNOESC Xanxerê. As medidas de altura de vilosidade e profundidade de cripta foram realizadas por meio do analisador de imagem "Image pro Plus 1.3.2" (1994) (aumento 40x) em microscópio óptico. De cada lâmina obtida foram selecionadas 30 vilosidades e 30 criptas, para obtenção do valor médio de cada corte apresentado. Para obtenção do valor de relação vilo:cripta, foi efetuada a divisão do valor da altura da vilosidade intestinal pelo valor de profundidade da cripta adjacente.

Para a avaliação dos parâmetros bioquímicos, utilizou-se o método de coleta de sangue através da veia braquial, coletando-se $1 \mathrm{ml}$ por animal, sendo realizadas aos 20 e 42 dias de idade. O soro foi separado por centrifugação e estocado a $20^{\circ} \mathrm{C}$ para posterior análise das concentrações séricas de glicose, proteínas totais, albumina, globulina, triglicerídeos totais, colesterol e ácido úrico. As provas bioquímicas foram efetuadas por meio de kit comercial, da marca Analisa, específicos para cada um dos referidos parâmetros, medidos em analisador semi-automático Bioplus 2000. Os níveis de globulinas foram determinados pela diferença entre proteínas totais e albumina. 
Os resultados experimentais obtidos foram submetidos ao teste de normalidade de Shapiro-Wilk, e posteriormente à análise de variância, e no caso de diferença significativa, as médias foram comparadas entre si pelo teste Tukey a 0,05 de significância, utilizando-se o software estatístico R.

\section{Resultados}

\section{Desempenho e rendimento de órgãos}

Os dados de desempenho da fase de 1-7 dias estão apresentados na Tabela 3, os quais mostraram haver diferenças significativas na conversão alimentar e na taxa de mortalidade das aves. Mostrou-se menor conversão alimentar $(\mathrm{P}<0,05)$ nas aves suplementadas com o blend de fitogênicos + leveduras nas aves pertencentes ao grupo controle negativo, quando comparadas às aves do tratamento controle positivo (Flavomicina). A mortalidade foi maior $(\mathrm{P}<0,05)$ nas aves pertencentes ao controle negativo.

Tabela 3. Desempenho de frangos de corte suplementados com diversos aditivos.

\section{1-7 dias}

\begin{tabular}{|c|c|c|c|c|c|}
\hline Tratamento & $\begin{array}{l}\text { Peso vivo } \\
(\mathrm{g})\end{array}$ & $\begin{array}{l}\text { Ganho de peso } \\
(\mathrm{g})\end{array}$ & $\begin{array}{l}\text { Consumo de } \\
\text { ração }(\mathrm{g})\end{array}$ & $\mathrm{CA}$ & Mortalidade \\
\hline Controle Negativo & 153 & 107 & 148 & $1,35 b$ & $5,65 b$ \\
\hline Flavomicina $15 \mathrm{ppm}$ & 153 & 107 & 151 & $1,40 \mathrm{a}$ & $0,00 \mathrm{a}$ \\
\hline Fitogênicos 200 ppm & 146 & 100 & 137 & $1,37 \mathrm{ab}$ & $0,00 \mathrm{a}$ \\
\hline $\begin{array}{c}\text { Fitogênicos + Leveduras } 200 \\
\text { ppm }\end{array}$ & 152 & 106 & 140 & $1,32 b$ & $0,00 \mathrm{a}$ \\
\hline Valor P & 0,142 & 0,142 & 0,215 & 0,035 & 0,044 \\
\hline $\mathrm{CV}(\%)$ & 7,23 & 7,16 & 8,11 & 5,32 & 9,22 \\
\hline \multicolumn{6}{|c|}{ 1-21 Dias } \\
\hline Tratamento & $\begin{array}{l}\text { Peso vivo } \\
\text { (g) }\end{array}$ & $\begin{array}{c}\text { Ganho de peso } \\
(\mathrm{g})\end{array}$ & $\begin{array}{l}\text { Consumo de } \\
\text { ração }(\mathrm{g})\end{array}$ & $\mathrm{CA}$ & Mortalidade (\%) \\
\hline Controle Negativo & 866 & 821 & 1127 & 1,37 & $6,70 \mathrm{~b}$ \\
\hline Flavomicina $15 \mathrm{ppm}$ & 864 & 816 & 1128 & 1,38 & $2,23 \mathrm{a}$ \\
\hline Fitogênicos 200 ppm & 811 & 752 & 1058 & 1,40 & $5,64 b$ \\
\hline $\begin{array}{c}\text { Fitogênicos }+ \text { Leveduras } 200 \\
\text { ppm }\end{array}$ & 863 & 815 & 1108 & 1,36 & $3,33 \mathrm{a}$ \\
\hline Valor P & 0,212 & 0,212 & 0,198 & 0,112 & 0,023 \\
\hline $\mathrm{CV}(\%)$ & 5,32 & 5,25 & 7,33 & 6,33 & 8,44 \\
\hline \multicolumn{6}{|c|}{ 1-42 Dias } \\
\hline Tratamento & $\begin{array}{l}\text { Peso vivo } \\
\text { (g) }\end{array}$ & $\begin{array}{l}\text { Ganho de } \\
\text { peso }(g)\end{array}$ & $\begin{array}{l}\text { mo de } \\
(\mathrm{g})\end{array}$ & Mortalidade & IEP \\
\hline Controle Negativo & $2715 \mathrm{a}$ & $2668 \mathrm{a}$ & 1,59 & $7,80 \% \mathrm{a}$ & 366 \\
\hline
\end{tabular}


Research, Society and Development, v. 10, n. 6, e4510615384, 2021

(CC BY 4.0) | ISSN 2525-3409 | DOI: http://dx.doi.org/10.33448/rsd-v10i6.15384

\begin{tabular}{ccccccc} 
Flavomicina 15ppm & $2690 \mathrm{ab}$ & $2649 \mathrm{ab}$ & 4384 & 1,62 & $4,45 \% \mathrm{~b}$ & 366 \\
Fitogênicos 200 ppm & $2656 \mathrm{~b}$ & $2606 \mathrm{~b}$ & 4295 & 1,62 & $7,80 \% \mathrm{a}$ & 361 \\
$\begin{array}{c}\text { Fitogênicos + Leveduras 200 } \\
\text { ppm }\end{array}$ & & & & & & \\
\hline Valor P & $2757 \mathrm{a}$ & $2707 \mathrm{a}$ & 4433 & 1,61 & $6,70 \% \mathrm{a}$ & 381 \\
CV (\%) & 0,046 & 0,045 & 0,284 & 0,195 & 0,039 & 0,145 \\
\hline
\end{tabular}

*Letras d iferentes na mesma coluna indicam diferença significativa a 0,05 de significância, através do teste Tukey. Fonte: Autores.

Diferenças significativas foram constatadas nas fases de 1-21 dias cujas aves suplementadas com Flavomicina apresentaram menor taxa de mortalidade $(\mathrm{P}<0,05)$. Não foram encontradas alterações $(\mathrm{P}>0,05)$ nos demais parâmetros nesta fase. No período de 1-42 dias de idade houve redução $(\mathrm{P}<0,05)$ do peso vivo e do ganho de peso nas aves suplementadas com 200 ppms dos fitogênicos carvacrol + cinnamaldeído. A taxa de mortalidade foi menor $(\mathrm{P}<0,05)$ nas aves pertencentes ao grupo que recebeu Flavomicina na dieta, não havendo modificações $(P>0,05)$ nos demais parâmetros avaliados entre os diferentes tratamentos testados.

Conforme verificado na Tabela 4, não foi constatada influência $(\mathrm{P}>0,05)$ da inclusão dos diferentes aditivos sobre os parâmetros de rendimento de órgãos (coração, fígado, proventrículo moela e intestino delgado).

Tabela 4. Rendimento de órgãos de frangos de corte suplementados com diversos aditivos aos 42 dias de idade.

\begin{tabular}{|c|c|c|c|c|c|}
\hline Tratamento & Coração (\%) & Fígado (\%) & Proventrículo (\%) & Moela (\%) & $\begin{array}{c}\text { Intestino Delgado } \\
(\%)\end{array}$ \\
\hline Controle Negativo & 0,51 & 2,44 & 0,32 & 1,59 & 3,18 \\
\hline Flavomicina 15ppm & 0,49 & 2,14 & 0,34 & 1,60 & 3,55 \\
\hline Fitogênicos 200 ppm & 0,46 & 1,87 & 0,36 & 1,45 & 3,58 \\
\hline $\begin{array}{c}\text { Fitogênicos }+ \text { Leveduras } 200 \\
\text { ppm }\end{array}$ & 0,45 & 2,17 & 0,32 & 1,36 & 3,50 \\
\hline Valor P & 0,266 & 0,351 & 0,395 & 0,264 & 0,255 \\
\hline $\mathrm{CV}(\%)$ & 11,23 & 13,35 & 9,21 & 9,34 & 13,55 \\
\hline
\end{tabular}

*Letras diferentes na mesma coluna indicam diferença significativa a 0,05 de significância, através do teste Tukey. Fonte: Autores.

\section{Histologia intestinal}

Os resultados obtidos da analise intestinal estão apresentados na Tabela 5, não havendo influência dos diferentes tratamentos sobre a altura das vilosidades intestinais dos frangos de corte $(\mathrm{P}>0,05)$. Entretanto, foram constatadas alterações significativas $(\mathrm{P}<0,05)$ na profundidade de cripta das aves, sendo maior nas aves suplementadas com Flavomicina quando comparadas com as aves que receberam os fitogênicos + leveduras na dieta. Ao avaliar-se a relação vilo/cripta, constata-se maior relação $(\mathrm{P}<0,05)$ nos frangos pertencentes ao tratamento fitogênicos + leveduras, em comparação às aves que receberam flavomicina na dieta. 
Tabela 5. Análise morfométrica intestinal de frangos de corte suplementados com diversos aditivos aos 42 dias de idade.

\begin{tabular}{|c|c|c|c|}
\hline Tratamento & Altura de Vilosidade & Profundidade de Cripta & Relação vilo:cripta \\
\hline Controle Negativo & 580,59 & $62,19 \mathrm{ab}$ & $9,56 \mathrm{ab}$ \\
\hline Flavomicina $15 \mathrm{ppm}$ & 605,72 & $71,93 a$ & $8,56 b$ \\
\hline Fitogênicos 200 ppm & 602,03 & $56,9 \mathrm{ab}$ & $11,17 \mathrm{ab}$ \\
\hline Fitogênicos + Leveduras 200 ppm & 650,35 & $50,55 b$ & $13,42 \mathrm{a}$ \\
\hline Valor P & 0,500 & 0,019 & 0,021 \\
\hline $\mathrm{CV}(\%)$ & 11,96 & 20,41 & 27,74 \\
\hline
\end{tabular}

*Letras diferentes na mesma coluna indicam diferença significativa a 0,05 de significância, através do teste Tukey. Fonte: Autores.

\section{Bioquímica sérica}

Não foram constatadas alterações significativas $(\mathrm{P}>0,05)$ em todos os nas análises de glicose, proteínas totais, albumina, globulina, triglicerídeos totais, colesterol e ácido úrico analisados entre as aves submetidas aos diferentes tratamentos avaliados (Tabela 6)

Tabela 6. Análise bioquímica sérica de frangos de corte suplementados com diversos aditivos aos 42 dias de idade.

\begin{tabular}{|c|c|c|c|c|c|c|c|}
\hline Tratamento & Glicose & $\begin{array}{c}\text { Proteínas } \\
\text { totais }\end{array}$ & Albumina & Globulina & $\begin{array}{c}\text { Triglicerídeos } \\
\text { totais }\end{array}$ & Colesterol & $\begin{array}{l}\text { Ácido } \\
\text { úrico }\end{array}$ \\
\hline Controle Negativo & 240 & 4,06 & 1,60 & 2,46 & 51,8 & 130 & 2,47 \\
\hline Flavomicina $15 \mathrm{ppm}$ & 235 & 4,52 & 1,58 & 2,94 & 45,8 & 125 & 2,56 \\
\hline Fitogênicos 200 ppm & 289 & 4,68 & 1,74 & 2,94 & 43,8 & 134 & 2,76 \\
\hline $\begin{array}{c}\text { Fitogênicos + Leveduras } 200 \\
\text { ppm }\end{array}$ & 241 & 4,64 & 1,36 & 3,28 & 52,4 & 116 & 2,30 \\
\hline Valor P & 0.963 & 0,862 & 0,565 & 0,561 & 0,857 & 0,333 & 0,671 \\
\hline $\mathrm{CV}(\%)$ & 22,42 & 25,23 & 25,32 & 15,32 & 23,12 & 22.12 & 21,34 \\
\hline
\end{tabular}

*Letras diferentes na mesma coluna indicam diferença significativa a 0,05 de significância, através do teste Tukey. Fonte: Autores.

\section{Discussão}

A melhora na conversão alimentar e a baixa mortalidade pode ser conferida aos efeitos antimicrobianos que possuem o carvacrol e cinnamaldeído. A atividade bacterina do carvacrol está relacionada com a ação sobre a membrana celular bacteriana impedindo sua divisão mitótica, causando desidratação nas células e, com isso, impedindo a sobrevivências de bactérias patogênicas. Já o cinnamaldeído são responsáveis por controlar a atividade antimicrobiana devido à sua lipofilicidade de terpenóides e fenilpropanóides que atravessam a membrana, alcançam o interior das células e danificam o sistema enzimático bacteriano.

Jeurissen et al. (2002) relatam que uma possível ausência de efeito no desempenho dos animais pode estar relacionada a composição da dieta basal utilizada e/ou às condições ambientais a que os animais são submetidos, como por exemplo superlotação. Resultados semelhantes foram achados por Lee et al. (2003) ao trabalharem em experimento com dose resposta de carvacrol e cinnamaldeído em resposta a diversos promotores de crescimento. Não foram achadas diferenças significativas 
no consumo de ração $(\mathrm{P}>0,05)$ e no ganho de peso $(\mathrm{P}>0,05)$ no período de 1-7 dias, comprovando não haver interferência no consumo normal das aves quando suplementadas com estes aditivos.

Muitos autores indicam que os aditivos fitogênicos utilizados em dietas para frangos de corte não apresentam efeitos muitos favoráveis quando comparamos ao desempenho. Como visto neste trabalho, a utilização de aditivos melhorou significativamente os índices zootécnicos, através de suas ações antibacterianas, anti-inflamatórias entre outras. Enfatizando com isso Barreto et al., (2008) achou resultados semelhantes desta pesquisa, citando que a utilização de carvacrol e cinnamaldeído obtiveram resultados significativos quando comparados ao tratamento controle e ao promotor.

O bom desempenho das aves alimentadas com aditivos nas fases de 1-21 e 22-42 dias pode ser explicado ao fato das aves terem consumido níveis adequados de aditivos, trazendo melhorias no sistema operacional das mesmas, através de reduções de estresse, conforto térmico adequado, diminuição de ataque de microrganismos, melhoria na produção de muco, produção de enzimas digestivas aumento da altura de vilosidades entre outras. Corduk et al. (2013), utilizando os mesmos óleos essências, relatou que das fases de 1-21 e 21-42 dias não se obteve resultados significativos esperados. Os mesmos autores dizem que essas ausências de efeitos dos óleos essências, estando relacionados a composição da deita basal, condições ambientais, e alojados sem que haja nenhum desafio sanitário.

Concomitantemente, os resultados achados nesta pesquisa estão de acordo com Leite et al. (2012), onde o mesmo cita que para que ocorra diferenças significativas entre tratamentos, é necessário induzir esses animais a um desafio sanitário. Contudo, esta pesquisa foi realizada sobre cama maravalha reutilizada, uma alternativa para aumentar o desafio. Porém, desafios maiores podem ser utilizados para se observar as ações dos aditivos fitogênicos sobre os animais.

Sobre o rendimento de órgãos ouve diferenças significativas sobre os tratamentos, sendo que se obteve um peso maior do fígado em aves pertencentes ao controle negativo. Esse aumento do peso de fígado pode ser explicado ao fato de que aves que não receberam nenhum aditivo via ração, apresentaram maior esforço para manter o equilíbrio internamente, ou seja, fígado foi sobrecarregado devido algum ataque de agentes patogênicos em alguma parte do organismo, onde o mesmo aumentou de tamanho para manter a devida função, o que representa lesão ou inflamação hepática.

A presença de cinnamaldeído, carvacrol e leveduras, apresentou tal aumento na altura das vilosidades, conforme proposto por Wang e Bourne (1998) citam que o cinnamaldeído apresentou ação estimulante sobre as enzimas pancreáticas, promovendo consequentemente redução na viscosidade intestinal, melhorando o processo digestivo. OETTING et al. (2006), observou que o carvacrol apresentou efeito antioxidante e antimicrobiano, através da qual o carvacrol age diretamente na membrana celular bacteriana, causando desidratação das células, impedindo sua divisão mitótica, impedindo a sobrevivência de bactérias patogênicas. Segundo Garcia et al. (2007), os probióticos que são fornecidos na ração melhoram o equilíbrio da microflora intestinal e modulação do sistema imunológico, reduzindo microrganismos patogênicos.

Concluído com o que se observou neste projeto, a adição de carvacrol, cinnamaldeído e leveduras em conjunto, apresenta efeitos benéficos para a metabolização dos nutrientes, através das ações, como antibacteriano, anticoccidiano, antifúngico, antioxidante, anti-inflamatório e sobre o sistema imune, vindo a contribuir com a saúde do animal e posteriormente melhorando os índices zootécnicos. De maneira grosseira, a utilização de carvacrol, cinnamaldeído e leveduras em conjunto, faz nos pensar que carvacrol e cinnamaldeído atuam contra agentes patogênicos, trazendo a morte dos mesmos, todavia a adição de leveduras serve para servir de alimento para agentes benéficos, fazendo com que o trato gastrointestinal melhore e ocorra uma melhor digestão e consequente absorção dos nutrientes.

Contudo, notou-se um melhor ganho de peso nas fases de 21-42 dias nas aves com o tratamento 4, quando comparadas aos outros tratamentos. LEE et al., (2004), comprovou uma maior atividade da enzima amilase aos 21 dias com uma mistura de óleos essenciais. Jang et al. (2007), utilizando o mesmo produto, também confirmou que a utilização de óleos essências aumentou a produção de tripsina, amilase e maltase até os 35 dias de idade. 
A junção carvacrol, cinnamaldeído e leveduras em conjunto, mostrou-se efetiva em relação aos outros tratamentos. A explicação deve ao fato de que esses aditivos ajudam a diminuir os impactos causados por bactérias patógenas na parede intestinal, atuando também na síntese de muco, aumento das enzimas digestivas e diminuição da carga bacteriana (Mustafa et al., 2006). Awaad et al. (2014), relatou um maior aumento das alturas de vilosidades quando comparadas a tratamentos controle.

Os parâmetros bioquímicos são de grande importância para avaliação clínica da saúde do animal. Nos indicam qual estado fisiológico essa ave se encontra, estado nutricional, patológico, e quais mudanças os aditivos na qual utilizamos, tem potencial para modificar de forma positiva ou negativa os parâmetros bioquímicos séricos. Em todos os tratamentos utilizados não forma observados alterações relevantes ( $\mathrm{P}>0,05)$. Hashemipour et al. (2013), citou que a utilização de carvacrol e cinnamaldeído juntos na dieta, proporcionou uma menor linear na relação heterófilo:linfócito. Contudo, o mesmo citou que o percentual de hematócrito, não foi influenciado pelas dietas experimentais. A utilização de carvacrol e cinnamaldeído nas dietas é uma alternativa aos antibióticos melhoradores de crescimento, na qual atuam na saúde intestinal como na manutenção do conteúdo de hemácias e hemoglobinas. Concomitantemente, a utilização destes extratos em dietas de frangos, ainda não observou resultados significativos em comparação a índices bioquímicos.

Já Al-Kassie (2009), apresentou resultados diferentes dos outros autores, citando que a utilização de carvacrol em dietas de frangos de corte influenciou diretamente os parâmetros bioquímicos, resultando em uma diminuição da taxa de heterofilo:linfócito, e concluíram que o mesmo pode agir de forma igual aos promotores de crescimento, sem causar danos de toxidade aos animais. Cardoso et al. (2008), também observou resultados significativos, onde aos 14 dias de idade houve aumento no número total e especifico de leucócitos e heterofilos em todos os grupos testados quando comparados aos tratamentos controle e, ou utilizados antibióticos, sugerindo um aumento da estimulação do sistema imunológico.

\section{Conclusão}

A inclusão do programa de aditivos composto pela combinação carvacrol e cinnamaldeído + leveduras pode substituir os antibióticos melhoradores de desempenho na alimentação de frangos de corte até 42 dias de idade, garantindo adequado desempenho produtivo, sem comprometer o peso relativo dos órgãos, a morfometria intestinal e a bioquímica sérica em frangos de corte. Estas informações servem de base para futuros trabalhos, que poderão validar mais precisamente opções de substituição de antibióticos na alimentação das aves.

\section{Agradecimentos}

Autores agradecem ao programa de bolsas universitárias de Santa Catarina - UNIEDU Art. 171, pela concessão da bolsa de iniciação científica.

\section{Referências}

Al-kassie, G. A. M. (2009). Influence of two plant extracts derived from thyme and cinnamon on broiler performance. Pakistan Veterinary Journal., 29(4), $169-173$.

Awaad, M. H. H., Elmenawey, M., \& Ahmed, K. A. (2014). Effect of a specific combination of carvacrol, cinnamaldehyde, and on the growth performance, carcass quality and gut integrity of broiler chickens. Veterinary World, 7(4), 284-290.

Barreto, M. S. R., Menten, J. F. M., Racanicci, A. M. C., Pereira, P. W. Z., \& Rizzo, P. V. (2008). Plant extracts used as growth promoters in broilers. Revista Brasileira de Ciência Avícola, 10, 109-115.

Barreto, M. S. R., Menten, J. F. M., Racanicci, A. M., Pereira, P. W. Z., \& Rizzo, P. V. (2008). Plant extracts used as growth promoters in broilers. Brazilian Journal of Poultry Science, 10(2), 109-115. 
Research, Society and Development, v. 10, n. 6, e4510615384, 2021

(CC BY 4.0) | ISSN 2525-3409 | DOI: http://dx.doi.org/10.33448/rsd-v10i6.15384

Bosetti, G. E., Griebler, L., Aniecevski, E., Facchi, C. S., Baggio, C., Rossatto, G., Leite, F., Valentini, F. D. A., Dal Santo, A., Pagnussatt, H., Boiago, M. M., \& Petrolli, T. G. (2020). Microencapsulated carvacrol and cinnamaldehyde replace growth-promoting antibiotics: Effect on performance and meat quality in broiler chickens. Anais da Academia Brasileida de Ciências, 92(3) e20200343.

Brasil (2013). Ministério da Ciência, Tecnologia e Inovação. Diretrizes para a prática de eutanásia do CONCEA, MCTI.

Cardoso, V. S., Lima, C. A. R., Lima, M. E. F., Dorneles, L. E. G., Filho, W. L. T., Lisboa, R. S., Junior, D. S. G., Direito, G. M., \& Danelli, M. G. M. (2008). Administração oral de piperina em frangos de corte. Ciência Rural., 39(5), 1521- 1526.

Corduk, M., Sarica, S., \& Yarim, G. F. (2007). Effects of oregano or red pepper essential oil supplementation to diets for broiler chicks with delayed feeding after hatching. 1. Performance and microbial population. The Journal of Applied Poultry Research, 22(4), 738-749.

Garcia, V., Gregori, P. C., Hernandez, F., Megias, M. D., \& Madrid, J. (2007). Effect of Formic Acid and Plant Extracts on Growth, Nutrient Digestibility, Intestine Mucosa Morphology, and Meat Yield of Broilers. Journal Applied Poultry Research, 16, 555-562.

Hashemipour, H., Kermanshashi, H., Golian, A., \& Veldkamp, T. (2013). Effect of thymol and carvacrol feed supplementation on performance, antioxidant enzyme activities, fatty acid composition, digestive enzyme activities, and immune response in broiler chickens. Poultry Science, 92, 2059-2069.

Jang, I. S., Ko, Y. H., Kang, S. Y., \& Lee, C. Y. (2007). Effect of a commercial essential oil on growth performance, digestive enzyme activity and intestinal microflora population in broiler chickens. Animal Feed Science and Technology, 134, 304- 315.

Jeurissen, S. H., Lewis, F., Van Der Klis, J. D., Mroz, Z., Rebel, J. M., \& Ter Huurne, A. A. (2002). Parameters and techniques to determine intestinal health of poultry as constituted by immunity, integrity and functionality. Current Issues in Intestinal Microbiology, 3, 1-14.

Lee, K. W., Everts, H., \& Beynen, A. C. (2004). Essential oils in broiler nutrition. International Journal of Poultry Science, 3, 738-752.

Leite, P., Mendes, F., Pereira, M., Lima, H. \& Lacerda, M. (2012). Aditivos fitogênicos em rações de frangos. Enciclopédia Biosfera, 8, 9-26.

Murshed, M. A., \& Abudabos, A. M. (2015). Effects of the Dietary Inclusion of a Probiotic, a Prebiotic or their Combinations on the Growth Performance of Broiler Chickens. Revista Brasileira de Ciência Avícola, 17(1), 99-103.

Mustafa, A., El-Medany, A., Hagar, H. H., \& El-Medany. G. (2006). Ginkgo biloba attenuates mucosal damage in a rat model of ulcerative colitis. Pharmacological Research, 53, 324-330.

Najafi, S. \& Taherpour, K. (2014). Effects of dietary ginger (Zingiber ofjicinale), cinnamon (Cinnamomum), symbiotic and antibiotic supplementation on performance of broilers. Journaul of Animal Science Advances, 4(1), 658-667.

Oetting, L. L., Utiyama, C. E.; Giani, P. A. et al. (2006). Efeito de extratos vegetais e antimicrobianos sobre a digestibilidade aparente, o desempenho, a morfometria dos órgãos e a histologia intestinal de leitões recém-desmamados. Revista Brasileira de Zootecnia, 35(4), 389-1397.

Opalinski, M., Maiorka, A., Dahlke, F., Cunha, F., Vargas, F.S.C., \& Cardozo, E. (2007). On the use of a probiotic (Bacillus subtilis - strain DSM 17299) as growth promoter in broiler diets. Revista Brasileira de Ciência Avícola, Campinas, 9(1), 99-103.

Pereira A. S. et al. (2018). Metodologia da pesquisa científica. UFSM.

Szakacs, A. R., Matei, S., Ștefănuț, L., Simcsak, R., \& Macri, A. (2015). The Impact of Pre and Probiotic on Growing Performance in Ross 708 Broiler Chickens. Bulletin UASVM Veterinary Medicine, Napoca., 72(2), 330-335.

Toghyani, M., Tohidi, M., Gheisari, A. A., \& Tabeidian, S. A. (2010). Performance, immunity, serum biochemical and hematological parameters in broiler chicks fed dietary thyme as alternative for an antibiotic growth promoter. African Journal of Biotechnology, 9(40), 6819-6825.

Zaghari, M., Zahroojian, N., Riahi, M., \& Parhizkar, S. (2016). Effect of Bacillus subtilis spore (GalliPro®) nutrients equivalency value on broiler chicken performance. Italian Journal of Animal Science, 14(1), 94-98. 